\title{
Regulatory Domains and Their Mechanisms
}

\author{
Nezha S. Benabdallah ${ }^{1,2}$ and Wendy A. Bickmore ${ }^{1}$ \\ ${ }^{1}$ MRC Human Genetics Unit, Institute of Genetics and Molecular Medicine, University of Edinburgh, \\ Edinburgh EH42XU, United Kingdom \\ ${ }^{2}$ Edinburgh Super Resolution Imaging Consortium, Institute of Genetics and Molecular Medicine, \\ University of Edinburgh, Edinburgh EH42XU, United Kingdom \\ Correspondence: wendy.bickmore@igmm.ed.ac.uk
}

\begin{abstract}
The concept of gene regulation is being refined as our understanding of the role of enhancer elements grows. Although described more than 30 years ago, the mechanisms through which these cis-regulating elements operate remain under debate. With the recognition that most of the human genetic variation contributing to common disease risk lies outside of genes and probably in enhancers, unraveling these mechanisms becomes ever more important. Originally, a popular view was to consider regulatory elements as an entry site for the transcription machinery that could scan the intervening chromatin until the cognate core promoter was located. Now, the most prominent model for distal enhancer-promoter interaction involves direct enhancer/promoter contacts with a looping out of intervening chromatin. However, a rising awareness of the importance of chromatin architecture and organization forces us to consider enhancer-promoter communication in light of the polymer folding properties of chromatin. Here, we discuss how three-dimensional chromatin folding, topological domains, and the constrained motion, plasticity, and accessibility of chromatin could offer a structural basis for regulatory domains that greatly enhances the probability of enhancer-promoter and transcription factor-promoter interactions and gene activation.
\end{abstract}

The definition of a gene has evolved significantly over the past 35 years. In metazoans, and particularly in mammals, the functional genetic unit now goes far beyond the genomic region that encodes an mRNA. $5^{\prime}$ elements adjacent to the transcription start site encompass the core promoter and serve as the docking site for the RNA polymerase II preinitiation complex (PIC). However, additional layers of complexity have emerged, including multiple alternative promoters, alternative exons, and cis-regulatory sequences positioned upstream, downstream, or even within an intron of the transcription unit.

Although the core promoter determines where transcription begins, the cis-regulatory sequences - or enhancers - stimulate promoters in a time and tissuespecific manner and increase the efficiency of transcription in a position- and orientation-independent manner. However, both enhancer and gene activation are associated with similar events - that is, recruitment of transcription factors, coactivators, and RNA polymerase II and production of RNA (albeit short and unstable at enhancers) (Koch et al. 2011). Therefore, enhancers have long been seen as simple extensions of promoters as both lead to assembly of an active transcription complex and are often bound by the same components (Andersson et al. 2015).

The first enhancer described was the 72-bp tandem repeat of SV40 DNA, which was identified as a sequence located $\sim 100 \mathrm{nt}$ upstream of the core early viral promoter (Fig. 1) and whose deletion reduced gene expression and abolished virus viability (Benoist and Chambon 1981; Gruss et al. 1981). Later, the SV40 enhancer was found to comprise three main segments, each of which provides cell type specificity (Schirm et al. 1987). In parallel, it was discovered that the SV40 enhancer could work when associated with other diverse promoters. Surprisingly, it could also act over considerable distances $(>10 \mathrm{~kb})$ and its activity appeared to rely on the sequence of the intervening chromatin rather than the distance (Banerji et al. 1981; Mellon et al. 1981; Moreau et al. 1981).

Other sequences with equivalent function in mammalian cells were soon identified (Conrad and Botchan 1982; Banerji et al. 1983), including locus control regions (LCRs) - which define regulatory domains that are groups of enhancers. The first LCR element identified $25-\mathrm{kb}$ upstream of the human $\varepsilon-, \gamma-, \delta$-, and $\beta$-globin genes (Fig. 1) shared characteristics of the SV40 enhancer including clustered DNase I hypersensitive sites (DHSs) (Grosveld et al. 1987; for review, see Li et al. 2002).

Now, human and mouse Mendelian genetics have revealed enhancers located up to 1 million base pairs (megabase $/ \mathrm{Mb}$ ) $5^{\prime}$ or $3^{\prime}$ of target genes (Fig. 1), often with other intervening genes located in-between, or embedded within the introns of nearby genes (Noonan and McCallion 2010). Thus, the functional unit of gene regulation in the mammalian genome, for coding regions that are themselves often $<10 \mathrm{~kb}$ in size, can be of the order of $2 \mathrm{Mb}$ in size.

Since they were first described, many of the molecular characteristics of enhancers have been established including transcription factor binding, coactivator recruitment, DHS, distinctive histone marks, and eRNA production. Here, we specifically consider the regulatory domains in which enhancers operate and how these domains may be 


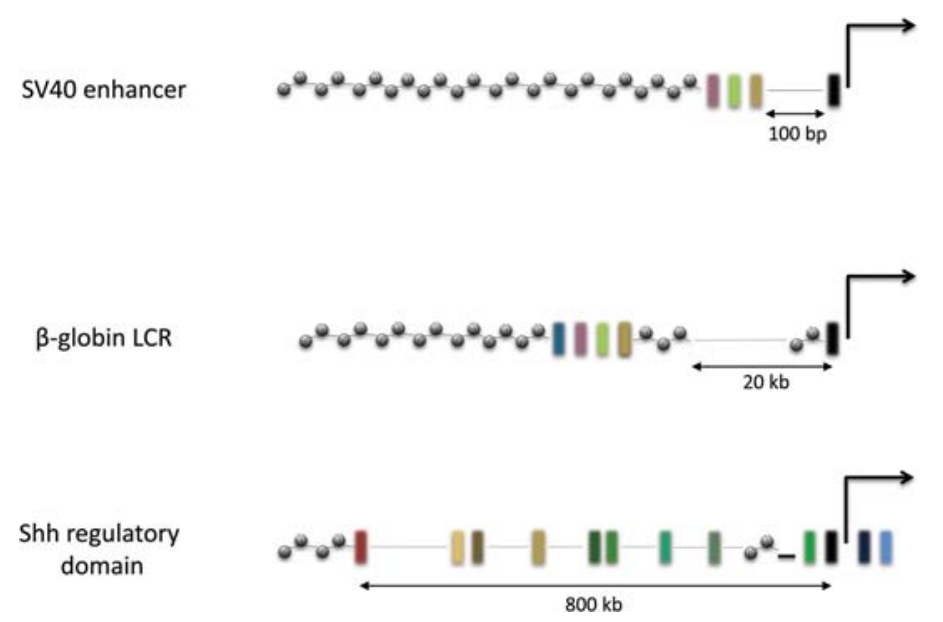

Figure 1. Different scales of enhancer and promoter distances. (Top) Proximal enhancers can be located a few tens of bp from their target promoter. An example of this is the SV40 early promoter. (Middle) Enhancers such as the $\beta$-globin locus control region (LCR) are located tens of kilobases from their target promoters. (Bottom) Some developmental enhancers can be located hundreds or even $1000 \mathrm{~kb}$ from their target gene, often with other, unrelated genes, in between. The Shh limb enhancer (ZRS) is an example of this.

integrated in specific chromatin conformations that influence enhancer-promoter communication.

\section{cis-ACTING ELEMENTS}

For the most part, enhancers function in cis. Exceptions include the ability of enhancers to work between homologous chromosomes in Drosophila cells that show somatic pairing (Schoborg et al. 2013) and the infrequent interaction of multiple enhancers-located on different chromosomes-with murine olfactory receptor genes, as the basis for stochastic choice in olfactory receptor gene expression in olfactory neurons (Markenscoff-Papadimitriou et al. 2014).

The requirement for a target gene and its enhancer to be located in cis, in order for gene activation to be robust, is evidenced by the Mendelian genetic disorders that arise when translocations separate enhancer and promoter onto different chromosomes (Kleinjan and van Heyningen 2005; Benko et al. 2009; Lango Allen et al. 2014; Rainger et al. 2014).

Genetic evidence indicates that enhancers can act over $1 \mathrm{Mb}$ of intervening chromatin. However, their range may not be much greater than this. Chromosomal inversions that increase the genomic distance between an enhancer and its target gene can, in some cases, abrogate enhancer function (Lettice et al. 2011).

Chromosome structural rearrangements have set the likely limits of enhancer function in the human genome and indicate that correct enhancer function usually depends on the enhancer being present within a range of $\sim 1 \mathrm{Mb}$ in $c$ is with its target gene. However, it is important to remember that enhancers are not constrained to have to work at a distance. Both enhancer reporter assays (Bhatia et al. 2015) and localized transposon hopping (Anderson et al. 2014; Symmons et al. 2014) show that endogenous mammalian enhancers that act at long range in their normal chromosomal context are quite capable of also acting at short range. It is within this framework that we now consider possible mechanisms of enhancer function in the context of three-dimensional chromatin conformation.

\section{SPREADING OF A SIGNAL: LINKING AND TRACKING MODELS}

The original view of regulatory element action was that it provided a precise docking site for RNA polymerase II or other components of the transcriptional machinery, followed by tracking of these factors on the chromatin fiber until they met the cognate core promoter and activated it in a time- and position-dependent manner.

Exploration of tracking-like mechanisms at several loci, such as $\beta$-globin, has reported the unidirectional spreading of histone $\mathrm{H} 3$ and $\mathrm{H} 4$ acetylation, the $\mathrm{CBP} / \mathrm{p} 300$ histone acetyltransferases, $\mathrm{P} / \mathrm{CAF}$, subunits of the SWI/SNF chromatin remodeling complex, or RNA polymerase II and TBP with accompanying synthesis of short, polyadenylated, intergenic RNAs (Gribnau et al. 2000; Hatzis and Talianidis 2002; Spicuglia et al. 2002; Masternak et al. 2003; Kim and Dean 2004; Zhao and Dean 2004; Wang et al. 2005; Zhu et al. 2007). These studies implicate tracking as the primary step for enhancer-promoter interaction and speculate that a stable enhancer-promoter loop is only formed when the tracking is complete (Fig. 2A). However, the formation of stable enhancer-promoter complexes has not always been convincingly shown. The linking hypothesis differs from the tracking mechanism, as the proteins involved do not scan all of the intervening chromatin but instead oligomerize to spread the signal (Fig. 2B).

In these examples of enhancer-promoter communication, the genomic distance separating the two elements is modest (generally $<20 \mathrm{~kb}$ ) and, from both kinetic and spatial perspectives, it is hard to imagine how one-dimensional tracking or linking mechanisms could operate over much larger (e.g., 1-Mb) distances and over intervening genes. 
A

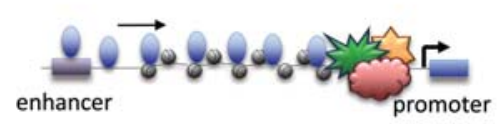

C

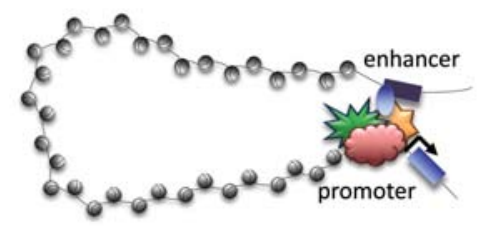

B

Linking
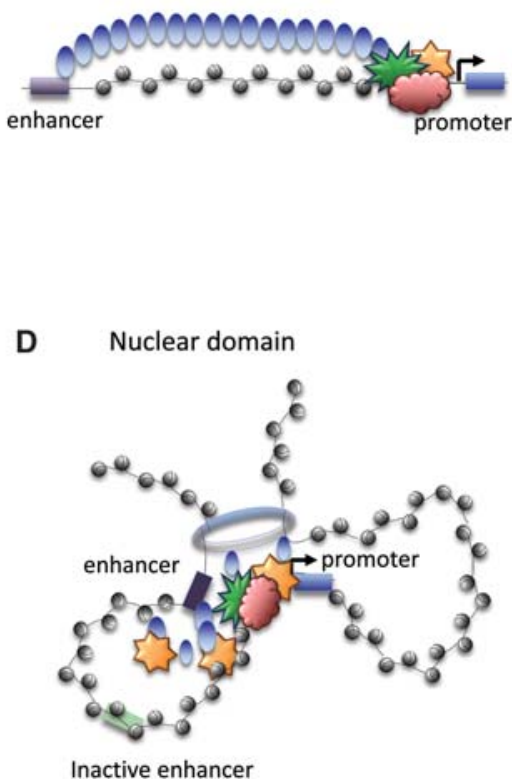

Figure 2. Enhancer and promoter communication mechanisms. Activating signals, such as transcription factors, bind enhancers recruiting other proteins, such as coactivators, that may track along the chromatin fiber until they meet their cognate promoter ( $A$ : tracking model) or oligomerize and form a protein bridge to meet their cognate promoter ( $B$ : linking model). Enhancer elements may be brought to the vicinity of their cognate promoter by direct interaction and looping out of the intervening chromatin region $(C$ : looping model), or enhancers may just be constrained within the same nuclear domain as their target genes with protein and chromatin constrained diffusion then being sufficient to activate gene expression ( $D$ : nuclear domain model).

\section{BRIDGING THE DIVIDE: THE CHROMOSOME LOOPING MODEL}

The current favored model for long-range enhancerpromoter communication involves direct homotypic or heterotypic interactions between enhancer- and promoter-bound proteins to form a chromatin loop that juxtaposes enhancer and promoter at the loop base and that loops out the intervening chromatin (Fig. 2C; Su et al. 1991).

Elegant chromosome engineering experiments at the $\beta$-globin locus have shown that forcing a chromosome loop between an enhancer and its target promoter is sufficient to trigger gene expression in erythroid cells, in which some other key transcription factors required for $\beta$-globin expression are already bound (Deng et al. 2012, Deng et al. 2014). However, the extent to which endogenous enhancers and promoters form relatively stable chromatin loops is currently unclear.

Much of the evidence for enhancer-promoter loops comes from the detection of enhancer-promoter ligation products in the chromosome conformation capture $(3 \mathrm{C})$ technique and its derivatives $(4 \mathrm{C}, 5 \mathrm{C}, \mathrm{Hi}-\mathrm{C}$, etc.) (Tolhuis et al. 2002; Palstra et al. 2003; Montavon et al. 2011; Jin et al. 2013). However, such assays do not have the ability to determine the frequency at which such interactions take place, to determine the molecular nature of such interactions, or to determine whether the interactions are the cause or consequence of enhancer-driven gene activation.

In some instances fluorescence in situ hybridization (FISH) has shown the spatial juxtaposition of distant enhancers and promoters at frequencies high enough ( $30 \%$ or more of alleles) to be interpreted as the base of a chromosome loop (Williamson et al. 2012; Lettice et al. 2014). However in other cases, visual assays do not provide evidence for relatively stable chromosome loops (Williamson et al. 2012). This does not exclude the existence of very transient enhancer-promoter contacts, but we would argue that such infrequent contacts should not be described as chromatin loops.

How enhancers and promoters find each other in nuclear space is not known, but it seems most likely that it occurs as a consequence of the rapid, but constrained,

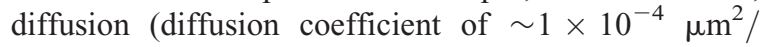
$\mathrm{sec}$ ) that characterizes chromatin motion in living human cells (Chubb et al. 2002). This implies that enhancers and their cognate promoters must both be located within a small enough nuclear volume to be compatible with the radius of constraint for chromatin motion. For the genomic loci measured to date, this constraint $(<0.5 \mu \mathrm{m})$ could encompass loci that are up to $\sim 1 \mathrm{Mb}$ from each other (Fig. 3A,B).

The formation of a stable chromatin loop has an entropic cost to polymer dynamics as it would need to overcome inherent diffusion. It would be interesting to investigate the strength of binding energies between enhancer- and promoter-bound proteins that would be required to stabilize chromatin loops of various sizes. This may be even more of an issue for enhancers located close to promoters, where the persistence length of the chroma- 
A non-expressing cell type

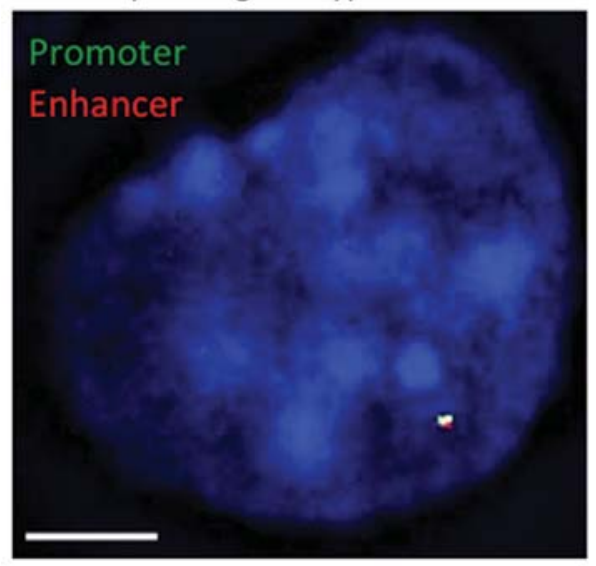

C

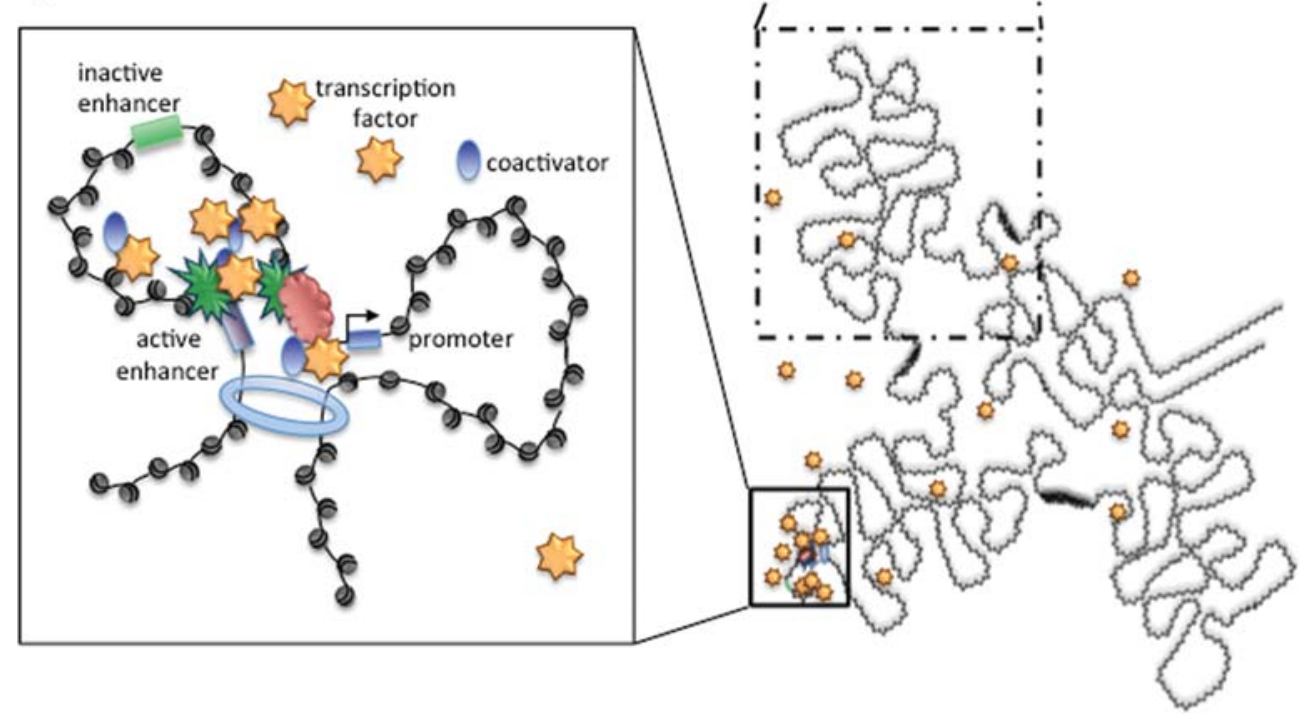

Figure 3. Chromatin compaction and constrained motion and its influence on transcription factor diffusion. ( $A$ ) FISH image illustrating a highly compact chromatin conformation of an inactive enhancer (red) and its cognate promoter (green), despite their being separated by several hundred kilobases, in the cell nucleus of a nonexpressing cell type. Scale bar, $5 \mu \mathrm{m}$. (B) Schematic representation of constrained chromatin motion ( $0.5 \mu \mathrm{m}$ average range) where chromatin can only sample a small proportion of the nuclear volume or indeed of the chromosome territory ( pale blue). Enhancers and their cognate promoters must be close enough to each other in nuclear space to be able to encounter each other through constrained diffusion. Scale bar, $5 \mu \mathrm{m}$. (Chubb and Bickmore 2003.) (C) Compact chromatin domains, such as topologically associated domains (TADs), and their viscoelastic properties, can affect the dimensionality of transcription factor diffusion and create compact volumes that can locally concentrate transcription factors, RNA polymerase, and coactivators.

tin polymer may be a further energetic barrier to loop formation.

\section{KEEPING IT CONCENTRATED: REGULATION WITHIN NUCLEAR DOMAINS}

The activation of gene expression requires the formation of protein-protein and protein-DNA complexes, the efficiency of which will be dependent on the laws of mass action and so will be very sensitive to local concentration of both proteins and DNA. Chromatin packaging may therefore be an important determinant of regulatory domains. In vivo analysis of the binding regimes of transcription factors shows that some use facilitated diffusion (i.e., 3D diffusion interspersed with local 1D sliding along the chromatin fiber). This greatly reduces their search space to give an efficient means of finding their specific binding sites (Chen et al. 2014; Izeddin et al. 2014; Woringer et al. 2014; Normanno et al. 2015). A transcription factor bound at an enhancer might then rather efficiently, by oversampling the local volume, be able to find a promoter-proximal binding site located 
within the same chromatin domain, obviating any need for a specific enhancer-promoter chromatin loop (Figs. 2D, 3C).

A second mode by which chromatin packing might affect enhancer function is by reducing the volume in which proteins involved in transcription (e.g., coactivators, components of the PIC) are free to diffuse and to form complexes with each other (excluded volume effect) (Woringer et al. 2014). Interestingly, $\sim 1 \mathrm{Mb}$ chromatin domains containing genes subject to complex developmental regulation that is driven by suites of enhancers appear to have a very compact chromatin structure, even in nonexpressing tissues (Fig. 3A; Williamson et al 2012; Lettice et al. 2014). This suggests that they may have evolved to facilitate both excluded volume and facilitated diffusion effects. Because of the viscoelastic properties of the nuclear environment, compact chromatin domains have been shown to affect chromatin motion and to dramatically reduce the first encounter time for distant genomic regions (Lucas et al. 2014).

A domain model for enhancer function may help to explain how primary and shadow enhancers, by both being contained in the same compact nuclear domain, could provide robustness to gene regulation during development, particularly when key molecules required for specific gene activation are limiting in the nucleus (Bothma et al. 2015; Lam et al. 2015). It also provides a plastic environment within which new enhancers can evolve to drive new patterns of gene regulation, or within which existing enhancers can relocate (Villar et al. 2015), without having to disrupt and rewire preexisting defined chromatin loops mediated by other enhancers in the same domain.

How such chromatin domains remain compact is unclear. It has been suggested that closed DNA domains could be formed by supercoiling with architectural proteins bound at the ends of these domains hindering the axial rotation that would relieve supercoiling (Duncan et al. 1994; Ner et al. 1994; Yang et al. 1995; Gilbert and Allan 2014). Indeed several studies have shown that enhancers and their target promoters tend to be located within the same topologically associated domains (TADs) — as defined from HiC data (Jin et al. 2013). In addition, reporter assays show that the influence of an enhancer declines sharply beyond the TAD domain boundary (Anderson et al. 2014; Symmons et al. 2014). Conversely, disrupting TAD boundaries can rewire enhancer and promoter communication leading to inappropriate gene activation (Lupiáñez et al. 2015).

What forms TAD boundaries is not completely clear, but convergently oriented CTCF sites, which also recruit cohesin, have been shown to be one important factor (Guo et al. 2015). The mechanistic basis for this is unclear, but it suggests the propagation of a directional signal from the boundary CTCF site in toward the TAD. Conceptually, this has some similarity to linking/tracking models of enhancer-promoter communication. However, the nature of that signal is unknown and it is likely that not all boundaries are the same.

\section{CONCLUSION}

Characterization of mammalian genomes using chromosome conformational capture techniques and microscopic imaging strongly support a model in which three-dimensional chromatin structures are organized into domains within which DNA-DNA and proteinDNA interactions are facilitated. It is within this framework that possible mechanisms of enhancer activation must be considered. Therefore, it becomes imperative that methods are developed that will allow the biophysical properties of chromatin domains and of transcription factor and chromatin motion to be quantified and manipulated in physiologically relevant systems.

\section{ACKNOWLEDGMENTS}

N.S.B. is supported by a Ph.D. studentship from the Edinburgh Super Resolution Imaging consortium (ESRIC). W.A.B. is supported by a Unit programme grant from the U.K. Medical Research Council. We thank Nick Gilbert (MRC HGU, Edinburgh) for critical reading of this manuscript.

\section{REFERENCES}

Anderson E, Devenney PS, Hill RE, Lettice LA. 2014. Mapping the Shh long-range regulatory domain. Development 141: 3934-3943.

Andersson R, Sandelin A, Danko CG. 2015. A unified architecture of transcriptional regulatory elements. Trends Genet $\mathbf{3 1}$ : 426-433.

Banerji J, Rusconi S, Schaffner W. 1981. Expression of a $\beta$-globin gene is enhanced by remote SV40 DNA sequences. Cell 27: 299-308

Banerji J, Olson L, Schaffner W. 1983. A lymphocyte-specific cellular enhancer is located downstream of the joining region in immunoglobulin heavy chain genes. Cell 33: 729-740.

Benko S, Fantes JA, Amiel J, Kleinjan DJ, Thomas S, Ramsay J, Jamshidi N, Essafi A, Heaney S, Gordon CT, et al. 2009. Highly conserved non-coding elements on either side of SOX9 associated with Pierre Robin sequence. Nat Genet 41: 359-364.

Benoist C, Chambon P. 1981. In vivo sequence requirements of the SV40 early promotor region. Nature 290: $304-310$.

Bhatia S, Gordon CT, Foster RG, Melin L, Abadie V, Baujat G, Vazquez MP, Amiel J, Lyonnet S, van Heyningen V, et al. 2015. Functional assessment of disease-associated regulatory variants in vivo using a versatile dual colour transgenesis strategy in zebrafish. PLoS Genet 11: e1005193.

Bothma JP, Garcia HG, Ng S, Perry MW, Gregor T, Levine M. 2015. Enhancer additivity and non-additivity are determined by enhancer strength in the Drosophila embryo. Elife 4. doi: 10.7554 /eLife.07956.

Chen J, Zhang Z, Li L, Chen BC, Revyakin A, Hajj B, Legant W, Dahan M, Lionnet T, Betzig E, et al. 2014. Single-molecule dynamics of enhanceosome assembly in embryonic stem cells. Cell 156: $1274-1285$.

Chubb JR, Bickmore WA. 2003. Considering nuclear compartmentalization in the light of nuclear dynamics. Cell 112: 403-406.

Chubb JR, Boyle S, Perry P, Bickmore WA. 2002. Chromatin motion is constrained by association with nuclear compartments in human cells. Curr Biol 12: 439-445.

Conrad SE, Botchan MR. 1982. Isolation and characterization of human DNA fragments with nucleotide sequence homologies 
with the simian virus 40 regulatory region. Mol Cell Biol 2: 949-965.

Deng W, Lee J, Wang H, Miller J, Reik A, Gregory PD, Dean A, Blobel GA. 2012. Controlling long-range genomic interactions at a native locus by targeted tethering of a looping factor. Cell 149: 1233-1244.

Deng W, Rupon JW, Krivega I, Breda L, Motta I, Jahn KS, Reik A, Gregory PD, Rivella S, Dean A, et al. 2014. Reactivation of developmentally silenced globin genes by forced chromatin looping. Cell 158: 849-860.

Duncan R, Bazar L, Michelotti G, Tomonaga T, Krutzsch H, Avigan M, Levens D. 1994. A sequence-specific, singlestrand binding protein activates the far upstream element of c-myc and defines a new DNA-binding motif. Genes Dev 8: $465-480$

Gilbert N, Allan J. 2014. Supercoiling in DNA and chromatin. Curr Opin Genet Dev 25: 15-21.

Gribnau J, Diderich K, Pruzina S, Calzolari R, Fraser P. 2000. Intergenic transcription and developmental remodeling of chromatin subdomains in the human $\beta$-globin locus. Mol Cell 5: 377-386.

Grosveld F, van Assendelft GB, Greaves DR, Kollias G. 1987. Position-independent, high-level expression of the human $\beta$ globin gene in transgenic mice. Cell 51: 975-985.

Gruss P, Dhar R, Khoury G. 1981. Simian virus 40 tandem repeated sequences as an element of the early promoter. Proc Natl Acad Sci 78: 943-947.

Guo Y, Xu Q, Canzio D, Shou J, Li J, Gorkin DU, Jung I, Wu H, Zhai Y, Tang Y, et al. 2015. CRISPR inversion of CTCF sites alters genome topology and enhancer/promoter function. Cell 162: 900-910.

Hatzis P, Talianidis I. 2002. Dynamics of enhancer-promoter communication during differentiation-induced gene activation. Mol Cell 10: 1467-1477.

Izeddin I, Récamier V, Bosanac L, Cissé II, Boudarene L, Dugast-Darzacq C, Proux F, Bénichou O, Voituriez R, Bensaude O, et al. 2014. Single-molecule tracking in live cells reveals distinct target-search strategies of transcription factors in the nucleus. Elife 3. doi: 10.7554/eLife.02230.

Jin F, Li Y, Dixon JR, Selvaraj S, Ye Z, Lee AY, Yen CA, Schmitt AD, Espinoza CA, Ren B. 2013. A high-resolution map of the three-dimensional chromatin interactome in human cells. Nature 503: 290-294.

Kim A, Dean A. 2004. Developmental stage differences in chromatin subdomains of the $\beta$-globin locus. Proc Natl Acad Sci 101: 7028-7033.

Kleinjan DA, van Heyningen V. 2005. Long-range control of gene expression: Emerging mechanisms and disruption in disease. Am J Hum Genet 76: 8-32.

Koch F, Fenouil R, Gut M, Cauchy P, Albert TK, ZacariasCabeza J, Spicuglia S, de la Chapelle AL, Heidemann M, Hintermair C, et al. 2011. Transcription initiation platforms and GTF recruitment at tissue-specific enhancers and promoters. Nat Struct Mol Biol 18: 956-963.

Lam DD, de Souza FS, Nasif S, Yamashita M, López-Leal R, Otero-Corchon V, Meece K, Sampath H, Mercer AJ, Wardlaw SL, et al. 2015. Partially redundant enhancers cooperatively maintain mammalian Pomc expression above a critical functional threshold. PLoS Genet 11: e1004935.

Lango Allen H, Caswell R, Xie W, Xu X, Wragg C, Turnpenny PD, Turner CL, Weedon MN, Ellard S. 2014. Next generation sequencing of chromosomal rearrangements in patients with split-hand/split-foot malformation provides evidence for $D Y N C 111$ exonic enhancers of $D L X 5 / 6$ expression in humans. $J$ Med Genet 51: 264-267.

Lettice LA, Daniels S, Sweeney E, Venkataraman S, Devenney PS, Gautier P, Morrison H, Fantes J, Hill RE, FitzPatrick DR. 2011. Enhancer-adoption as a mechanism of human developmental disease. Hum Mutat 32: 1492-1499.

Lettice LA, Williamson I, Devenney PS, Kilanowski F, Dorin J, Hill RE. 2014. Development of five digits is controlled by a bipartite long-range cis-regulator. Development 141: 17151725.
Li Q, Peterson KR, Fang X, Stamatoyannopoulos G. 2002. Locus control regions. Blood 100: 3077-3086.

Lucas JS, Zhang Y, Dudko OK, Murre C. 2014. 3D trajectories adopted by coding and regulatory DNA elements: First-passage times for genomic interactions. Cell 158: 339-352.

Lupiáñez DG, Kraft K, Heinrich V, Krawitz P, Brancati F, Klopocki E, Horn D, Kayserili H, Opitz JM, Laxova R, et al. 2015. Disruptions of topological chromatin domains cause pathogenic rewiring of gene-enhancer interactions. Cell 161: $1012-1025$.

Markenscoff-Papadimitriou E, Allen WE, Colquitt BM, Goh T, Murphy KK, Monahan K, Mosley CP, Ahituv N, Lomvardas S. 2014. Enhancer interaction networks as a means for singular olfactory receptor expression. Cell 159: 543-557.

Masternak K, Peyraud N, Krawczyk M, Barras E, Reith W. 2003. Chromatin remodeling and extragenic transcription at the MHC class II locus control region. Nat Immunol 4: 132-137.

Mellon P, Parker V, Gluzman Y, Maniatis T. 1981. Identification of DNA sequences required for transcription of the human alpha 1-globin gene in a new SV40 host-vector system. Cell 27: $279-288$.

Montavon T, Soshnikova N, Mascrez B, Joye E, Thevenet L, Splinter E, de Laat W, Spitz F, Duboule D. 2011. A regulatory archipelago controls Hox genes transcription in digits. Cell 147: $1132-1145$.

Moreau P, Hen R, Wasylyk B, Everett R, Gaub MP, Chambon P. 1981. The SV40 72 base repair repeat has a striking effect on gene expression both in SV40 and other chimeric recombinants. Nucleic Acids Res 9: 6047-6068.

Ner SS, Travers AA, Churchill ME. 1994. Harnessing the writhe: A role for DNA chaperones in nucleoprotein-complex formation. Trends Biochem Sci 19: 185-187.

Noonan JP, McCallion AS. 2010. Genomics of long-range regulatory elements. Annu Rev Genomics Hum Genet 11: $1-23$.

Normanno D, Boudarène L, Dugast-Darzacq C, Chen J, Richter C, Proux F, Bénichou O, Voituriez R, Darzacq X, Dahan M. 2015. Probing the target search of DNA-binding proteins in mammalian cells using TetR as model searcher. Nat Commun 6: 7357.

Palstra RJ, Tolhuis B, Splinter E, Nijmeijer R, Grosveld F, de Laat W. 2003. The $\beta$-globin nuclear compartment in development and erythroid differentiation. Nat Genet 35: 190194.

Rainger JK, Bhatia S, Bengani H, Gautier P, Rainger J, Pearson M, Ansari M, Crow J, Mehendale F, Palinkasova B, et al. 2014. Disruption of SATB2 or its long-range cis-regulation by SOX9 causes a syndromic form of Pierre Robin sequence. Hum Mol Genet 23: 2569-2579.

Schirm S, Jiricny J, Schaffner W. 1987. The SV40 enhancer can be dissected into multiple segments, each with a different cell type specificity. Genes Dev 1: 65-74.

Schoborg T, Kuruganti S, Rickels R, Labrador M. 2013. The Drosophila gypsy insulator supports transvection in the presence of the vestigial enhancer. PLoS One 8: e81331.

Spicuglia S, Kumar S, Yeh JH, Vachez E, Chasson L, Gorbatch S, Cautres J, Ferrier P. 2002. Promoter activation by enhancerdependent and -independent loading of activator and coactivator complexes. Mol Cell 10: 1479-1487.

Su W, Jackson S, Tjian R, Echols H. 1991. DNA looping between sites for transcriptional activation: Self-association of DNA-bound Sp1. Genes Dev 5: 820-826.

Symmons O, Uslu VV, Tsujimura T, Ruf S, Nassari S, Schwarzer W, Ettwiller L, Spitz F. 2014. Functional and topological characteristics of mammalian regulatory domains. Genome Res 24: 390-400.

Tolhuis B, Palstra RJ, Splinter E, Grosveld F, de Laat W. 2002. Looping and interaction between hypersensitive sites in the active $\beta$-globin locus. Mol Cell 10: 1453-1465.

Villar D, Berthelot C, Aldridge S, Rayner TF, Lukk M, Pignatelli M, Park TJ, Deaville R, Erichsen JT, Jasinska AJ, et al. 2015. Enhancer evolution across 20 mammalian species. Cell 160: $554-566$. 
Wang Q, Carroll JS, Brown M. 2005. Spatial and temporal recruitment of androgen receptor and its coactivators involves chromosomal looping and polymerase tracking. Mol Cell 19: $631-642$.

Williamson I, Eskeland R, Lettice LA, Hill AE, Boyle S, Grimes GR, Hill RE, Bickmore WA. 2012. Anterior-posterior differences in HoxD chromatin topology in limb development. Development 139: 3157-3167.

Woringer M, Darzacq X, Izeddin I. 2014. Geometry of the nucleus: A perspective on gene expression regulation. Curr Opin Chem Biol 20: $112-119$.
Yang Y, Westcott TP, Pedersen SC, Tobias I, Olson WK. 1995. Effects of localized bending on DNA supercoiling. Trends Biochem Sci 20: 313-319.

Zhao H, Dean A. 2004. An insulator blocks spreading of histone acetylation and interferes with RNA polymerase II transfer between an enhancer and gene. Nucleic Acids Res 32: $4903-$ 4919.

Zhu X, Ling J, Zhang L, Pi W, Wu M, Tuan D. 2007. A facilitated tracking and transcription mechanism of longrange enhancer function. Nucleic Acids Res 35: 55325544. 


\section{$\$_{\text {CSH }}^{\infty}$ Cold Spring Harbor Symposia SYMPOSIA On Quantitative Biology}

\section{Regulatory Domains and Their Mechanisms}

Nezha S. Benabdallah and Wendy A. Bickmore

Cold Spring Harb Symp Quant Biol 2015 80: 45-51 originally published online November 20, 2015

Access the most recent version at doi:10.1101/sqb.2015.80.027268

References This article cites 56 articles, 12 of which can be accessed free at:

http://symposium.cshlp.org/content/80/45.full.html\#ref-list-1

License

Email Alerting Receive free email alerts when new articles cite this article - sign up in Service the box at the top right corner of the article or click here. 